\title{
AS CONTRIBUIÇÕES DO MODERNISMO PARA A LITERATURA E A CRÍTICA BRASILEIRAS
}

Larissa Agostini Cerqueira Mestranda em Literatura / UFMG

\begin{abstract}
RESUMO
Este artigo pretende investigar de que forma o movimento modernista brasileiro contribuiu para a formação ou a consolidação de uma literatura brasileira moderna, por meio da renovação de padrões estéticos e políticosociais, por um lado, e, por outro, que herança o movimento deixou para a produção crítico-literária do país.
\end{abstract}

PALAVRAS-CHAVE

Modernismo, literatura brasileira, crítica literária brasileira

\section{INTRODUÇÃO}

Pode-se afirmar, com base nos estudos sobre o modernismo, que o movimento no Brasil - assim como as vanguardas na Europa - teve um caráter predominantemente destruidor, pelo menos em princípio. Isso ocorreu porque, para superar as barreiras do passadismo e do academismo era necessário um espírito revolucionário que rompesse com os padrões herdados e, a partir dessa ruptura, criasse uma literatura atual e nacional, isto é, moderna. Uma vez que o objetivo era construir uma nova literatura, é preciso ressaltar que o caráter destruidor da vanguarda brasileira pertence apenas à sua fase inicial, provocativa, que foi seguida de uma fase mais estável e produtiva, dentro dos novos padrões estéticos.

O objetivo deste trabalho é verificar o impacto que a ruptura modernista causou na produção literária do país, isto é, que mudanças e contribuições o modernismo trouxe para a literatura nacional e, em segundo lugar, quais as consequências dessa transformação estética para a crítica literária produzida no país.

Não se pode esquecer que o modernismo - mesmo se considerarmos o movimento de forma restrita, isto é, restringi-lo temporalmente à década de 1920, como o faz o teórico 
Álvaro Lins ${ }^{1}$ - não foi de forma alguma homogêneo e seu impacto também foi diferenciado, como nos mostra por exemplo o estudo de Maria Eugênia Boaventura sobre a revista modernista Movimento Brasileiro, ${ }^{2}$ dirigida por Graça Aranha e seu grupo. A autora ressalta como característica intrínseca ao modernismo a formação de grupos, o que o diferencia de outros movimentos artísticos, que não tinham a mesma exigência, ou às vezes até valorizavam o indivíduo em detrimento do grupo. Esse fenômeno de formação de grupos diversos dentro do movimento trouxe como consequência várias vertentes que, se tinham um projeto em comum, tinham também visões diversas do que esse projeto significava na prática e de como implementá-lo. No trabalho ora citado de Boaventura são muito claras as divergências entre o grupo paulista e o carioca. Enquanto o primeiro, encabeçado por Mário e Oswald de Andrade, foi um grupo que implementou a inovação técnica e linguística em suas obras e tinha uma posição intelectual vanguardista, o segundo tinha caráter ufanista e politicamente reacionário, e era esteticamente apegado aos valores passadistas combatidos no seu próprio discurso.

O foco do presente trabalho será a obra de Mário de Andrade, por três razões: primeiro, porque o escritor foi um dos artistas precursores e um dos principais teóricos da primeira fase do movimento, com os textos "Prefácio interessantíssimo” - integrante do livro apresentado na Semana de Arte Moderna, Paulicéia desvairada - e A escrava que não é Isaura; a segunda razão para a escolha do poeta, é que ele tem uma obra de crítica literária e artística vasta e rica, que o torna um dos representantes de vulto da atividade crítica no Brasil; e, em terceiro lugar, porque, tanto como escritor, quanto como crítico, sua obra pode ser considerada uma das mais bem-sucedidas do movimento modernista, dentro do que ele propunha: uma ruptura estética e ideológica dos padrões sociais em voga no Brasil no início do século 20. Exemplos que comprovam essa visão são Macunaíma, considerada ainda uma das obras mais representativas do movimento, assim como O empalhador de passarinho e Aspectos da literatura brasileira, dois livros que reúnem os principais ensaios críticos do autor. A característica principal que faz de sua obra uma das mais representativas da época é o aguçado senso crítico e a sensibilidade aos problemas de seu tempo, fossem eles de ordem estética ou social e política.

\section{TEMPOS MODERNOS E MODERNISMO NO BRASIL}

\footnotetext{
${ }^{1}$ LINS. Filosofia, história e crítica na literatura brasileira: Afrânio Peixoto, João Ribeiro, José Veríssimo, Mário de Andrade, Lúcia Miguel Pereira.

${ }^{2}$ BOAVENTURA. Movimento Brasileiro: contribuição ao estudo do modernismo.
} 
O projeto de inovação da literatura no Brasil se deu por meio da ruptura com os rígidos padrões parnasianos, com o objetivo de criar uma literatura genuinamente nacional e atual que correspondesse às exigências de seu tempo. A fim de compreender o que essa ruptura significou para a literatura, é necessário analisá-la mais a fundo. Antes de mais nada, é preciso voltar à origem da ruptura, ou ainda, à origem do espírito revolucionário que a provocou para, em seguida, compreender as consequências geradas por ela. A necessidade desta análise se dá porque a inovação estética - pelo menos no caso do modernismo - pode ser considerada uma espécie de incorporação, no âmbito estético, de uma nova realidade. ${ }^{3}$ Neste caso, seria a incorporação de valores modernos à literatura e às artes em geral. As formas artísticas antigas deixaram de atender às novas exigências e aqueles que se apegam a elas não passam de imitadores de fórmulas não mais eficazes. Sendo assim, pode-se concluir que a ruptura de padrões estéticos que ocorreu no modernismo foi o reflexo das transformações vividas pela sociedade da época. Sua origem é, portanto, a própria imposição da realidade.

O crítico Álvaro Lins salienta que o movimento - no Brasil e em todos os países que participaram de alguma forma da Primeira Guerra Mundial - era um reflexo, na literatura, das mudanças de valores que estavam ocorrendo na sociedade: "Efetivamente, eis o que foi o modernismo: uma crise, uma fase de transição, uma imagem de instabilidade social."4 É correto afirmar que a guerra não foi o único fator determinante da modernidade nas sociedades, uma vez que países que não participaram diretamente dela nem sofreram suas consequências mais graves também passaram por um processo de modernização. Esse tema é muito mais complexo e há várias outras variantes, como a industrialização das sociedades e as suas consequentes mudanças, como a aglomeração de populações em grandes centros urbanos, o surgimento de novas classes sociais (a burguesia urbana e o proletariado), o desenvolvimento da indústria do entretenimento e dos meios de comunicação. Todas essas mudanças causaram uma necessidade de transformação nas artes também, pois o que era produzido não condizia mais com as condições do homem moderno.

\footnotetext{
${ }^{3}$ Álvaro Lins considera modernista todo movimento de inovação artística em períodos de estagnação, e considera moderna toda arte que é fruto desses movimentos e, portanto, está de acordo com seu tempo: "Sempre um movimento modernista apareceu quando era oportuno uma literatura retomar o seu destino de ser moderna.” Não achamos necessário, no entanto, para os fins a que este trabalho se propõe, aprofundar essa questão, uma vez que nosso trabalho aborda o modernismo historicamente, como o movimento brasileiro de vanguarda que teve início na segunda década do século 20. LINS. A liderança literária, o ensaio e a crítica em Mário de Andrade, p. 73.

${ }^{4}$ LINS. A liderança literária, o ensaio e a crítica em Mário de Andrade, p. 77.
} 
Porém, é importante salientar o caráter dialético da relação entre literatura e realidade. Como afirmado anteriormente, a origem de sua transformação é a própria transformação social. Não se pode, no entanto, parar por aí. Uma vez incorporadas como formas às novas exigências de um tempo, a literatura passa a repercutir sobre a sociedade, contribuindo para a transformação da consciência nacional e a solução de problemas. Álvaro Lins fala de um projeto de História Literária do Brasil, baseado no ímpeto de escritores de todos os tempos em influenciar a realidade do país, constituindo-se em homens públicos por meio de suas obras e assumindo, dessa forma, “um papel de vanguarda na investigação e apresentação dos grandes problemas brasileiros”. ${ }^{5}$ Esse espírito de vanguarda foi especialmente importante no modernismo, pois, como o próprio Mário de Andrade afirma, não foi um movimento estético, mas um espírito revolucionário acima de tudo, uma vez que o seu tempo era um tempo de politização do homem e que exigia, dessa forma, o engajamento da arte na vida:

A transformação do mundo (...) bem como o desenvolvimento da consciência americana e brasileira, (...) impunham a criação de um espírito novo e exigiam a reverificação e mesmo a remodelação da Inteligência nacional. Isso foi o movimento modernista (...). ${ }^{6}$

\section{MODERNISMO E LITERATURA MODERNA BRASILEIRA}

No Brasil, o modernismo teve uma conjuntura bastante singular, se comparado às vanguardas europeias, caracterizadas por artistas que, em sua maioria, viviam às margens da sociedade burguesa (mesmo que muitos tivessem origem em famílias burguesas) e se voltaram contra os valores dessa sociedade. Em São Paulo, os vanguardistas foram financiados pela burguesia agrária, que promovia os famosos salões de arte e viagens à Europa, interessada não somente na estética modernizante, mas também e sobretudo no retorno às origens e tradições culturais do Brasil. Se nessas origens os modernistas buscavam a feição genuinamente brasileira da arte, a burguesia agrária buscava uma forma de se fortalecer e se impor na nova configuração econômica do país, que teve como consequência a ascensão de uma nova classe burguesa, urbana e industrial. Essa peculiaridade na conjuntura de surgimento do modernismo brasileiro tem, sem dúvida, implicações sobre o movimento como, por exemplo, obras que não apresentam uma atitude politicamente crítica, como o próprio Mário de Andrade admitirá na década de 1940. No entanto, mesmo que haja um consenso de que num primeiro momento o modernismo teve como foco principal a questão

\footnotetext{
${ }^{5}$ LINS. Por uma história literária do Brasil e por uma literatura brasileira, p. 119.

${ }^{6}$ ANDRADE. O movimento modernista, p. 231.
} 
puramente estética, a consciência política será uma das consequências dos avanços alcançados na inovação da linguagem artística, como veremos mais detalhadamente.

Analisemos pois essas contribuições do movimento modernista à literatura e à sociedade brasileiras. Na conferência denominada “O Movimento Modernista”, Mário de Andrade enumera três princípios fundamentais, cuja fusão pelo modernismo caracterizou uma mudança drástica da realidade brasileira: a conquista da liberdade de pesquisa estética, a atualização da Inteligência artística nacional e a estabilização de uma consciência criadora nacional. Segundo sua análise, a fusão desses três fatores foi responsável pela conquista da independência do Brasil em termos artísticos e intelectuais, da liberdade criadora e da originalidade das produções artísticas, isto é, da conquista de uma literatura nacional e atual. Álvaro Lins ressalta que somente uma literatura feita com liberdade de pesquisa e que busca material na cultura local pode ser atual, pois é nacional e contemporânea e, portanto, apta a atingir o status de universal. O autor afirma que "não podemos aspirar a uma posição internacional enquanto não tivermos levantado uma forte, nítida e bem caracterizada fisionomia nacional.,"7

É importante lembrar que essas normas não são consideradas originais pelo próprio Mário de Andrade. Ele tem plena noção de que todas elas podem ser encontradas em outros movimentos artísticos brasileiros. A grande diferença instaurada pelo modernismo "foi a conjugação dessas três normas num todo orgânico da consciência coletiva”. 8 Esse "todo orgânico”, porém, não pode ser considerado harmônico de forma alguma. O próprio crítico admite que essas conquistas tiveram pesos diferentes.

Com relação ao campo da literatura, pode-se dizer que o modernismo trouxe duas principais contribuições: uma nova consciência do ato da criação, que passaria a ser um ato independente de pesquisa estética e de libertação dos padrões e técnicas preestabelecidos; e a consciência de que a obra de arte é um fazer mais coletivo e funcional do que individual e psicológico, e o que mais importa nela é esse caráter coletivo. Isso significa que, pela primeira vez na história da literatura brasileira, houve uma preocupação e uma efetiva fundação de um espírito coletivo criativo (a que Mário de Andrade chama de estabilização da consciência criadora nacional), uma noção de literatura nacional, produzida a partir da pesquisa estética e não por imitação de um determinado padrão estético em voga. Com relação a essa vitória, Jorge Schwartz lembra a importância do modernismo para a literatura brasileira, ressaltando a

\footnotetext{
${ }^{7}$ LINS. A liderança literária, o ensaio e a crítica em Mário de Andrade, p. 118.

${ }^{8}$ ANDRADE. O movimento modernista, p. 242.
} 
diferença fundamental entre a poética modernista e as que a antecederam:

Nestas há leis de bom proceder, há “Don’t”, há manuais do bom conselheiro, há regras de preconceito artístico, teias concêntricas da Beleza imitativa (...). Na orientação modernizante seguem-se indicações largas dentro das quais se move com prazer a liberdade individual. Não se encontra nela regras de arame farpado que constrangem senão indicações que facilitam. ${ }^{9}$

Para Mário de Andrade, essa foi a grande conquista do modernismo. Apesar de considerar insuficientes as tentativas de revisão da língua portuguesa, para adequá-la à nossa realidade e para que "nos expressássemos com identidade"10 (opinião que diverge de Álvaro Lins, que considera a nossa língua bastante diversa da "portuguesa” e considera exageradas e mesmo equivocadas as tentativas de Mário de Andrade e de outros modernistas de adaptá-la, trazendo a linguagem oral para a literatura), o escritor considera que a expressão nacional na literatura - assim como em outras artes - era um avanço irrefutável. O autor analisa as produções das décadas de 1920 e 1940, e reitera que estava sendo produzida literatura moderna no Brasil.

No entanto, no âmbito social (ou no que o autor chama de atualização da Inteligência artística, que engloba, além do caráter estético, o caráter social da arte), Mário de Andrade se ressente de ter permitido o "burguês gostoso" ter se sobreposto ao "intelectual consciente" e por não pegar “a máscara do tempo e esbofeteá-la como ela merece”. ${ }^{11}$ Para o crítico, a geração de 1920 pecou por ausência de realidade e de virilidade, isto é, por falta de engajamento real nos problemas de seu tempo, problemas esses fundamentalmente sociais e políticos. Seu julgamento é sem dúvida severo demais, uma das consequências de seu espírito crítico por natureza. Como veremos a seguir, há estudos a respeito do movimento que conseguem, com um distanciamento maior, apontar diferentes fases no modernismo e na própria obra de Mário de Andrade, em que, ora o aspecto estético, ora o político-social se sobressaem. A partir desses estudos, verificamos que as obras mais tardias já incorporaram uma atitude estética inovadora e passam a trazer uma carga muito maior de senso de realidade e de crítica social. Porém, o crítico é implacável com o escritor:

E apesar de nossa atualidade, da nossa nacionalidade, da nossa universalidade, uma coisa não ajudamos verdadeiramente, duma coisa não participamos: o amilhoramento político-social do homem. E esta é a essência

\footnotetext{
${ }^{9}$ SCHWARTZ. Vanguardas latino-americanas: polêmicas, manifestos e textos críticos, p. 130.

${ }^{10}$ ANDRADE. O movimento modernista, p. 244.

${ }^{11}$ ANDRADE. O movimento modernista, p. 253.
} 
da nossa idade. ${ }^{12}$

João Luiz Lafetá considera que o movimento modernista foi em todos os momentos formado pela interação de duas esferas: a ideológica e a estética. Para ele, a necessidade de engajamento com os problemas de seu tempo era algo intrínseco ao movimento e caracteriza seu âmbito ideológico. ${ }^{13}$ Já a ruptura da linguagem academista e a incorporação do popular e do primitivo caracterizam seu âmbito estético. Esses dois aspectos nunca se separam na literatura, mas vivem em constante tensão.

Para o autor, o modernismo teve duas fases caracterizadas pela predominância de cada um desses aspectos, em detrimento do outro. Mas num certo momento, compreendido na segunda fase, parece ter havido um equilíbrio de forças entre eles, que em seguida se diluiu. Na primeira fase, que compreende as produções da década de 1920, chamada pelo autor de "fase heroica”, teria havido uma predominância do caráter estético da literatura: “A experimentação estética é revolucionária e caracteriza fortemente os primeiros anos do movimento.”" Essa avaliação está de acordo com a avaliação de Mário de Andrade, se tomarmos suas considerações a respeito da grande vitória do movimento, que teria sido nas suas conquistas estéticas. Quando Andrade fala do movimento na conferência abordada neste trabalho, ele se refere à geração de 1920, aos artistas da Semana de Arte Moderna, sempre em contraste com a geração posterior, dos artistas da década de 1940. Lafetá chama a atenção para o fato de que a ruptura da linguagem e o seu desnudamento no interior da obra literária eram ações primordiais na “fase heroica” do modernismo. Somente por meio dessas conquistas no campo estético, o modernismo seria capaz de atingir seu objetivo: inovar a literatura nacional. Nesse momento, apesar de as obras terem atitude crítica perante os conflitos da realidade, seu tom era mais ameno.

Já numa segunda fase, que compreende para Lafetá a década de 1930, as conquistas estéticas já estavam consolidadas e amadurecidas, “superando os modismos e os cacoetes dos anos vinte, abandonando o que era pura contingência ou necessidade do período de combate estético”. ${ }^{15}$ Diante dessa nova realidade, o caráter ideológico passou a assumir uma posição

\footnotetext{
${ }^{12}$ ANDRADE. O movimento modernista, p. 255.

13 Neste trabalho, equivale ao que denominamos âmbito político-social da arte, uma vez que o termo ideológico é datado, que hoje em dia tem um campo semântico restrito, o que o torna incapaz de transmitir o significado pretendido pelo autor. Dessa forma, será utilizado o termo escolhido por Lafetá, quando nos referirmos à sua obra, em itálico.

${ }^{14}$ LAFETÁ. 1930: a crítica e o modernismo, p. 21.

${ }^{15}$ LAFETÁ. 1930: a crítica e o modernismo, p. 31.
} 
de destaque nas obras. O engajamento nos problemas do seu tempo não era apenas tema na poesia moderna. Deveria ser muito mais que isso: a irreverência e a inconformidade perante os problemas era uma característica interna da literatura moderna, uma exigência que se impunha aos artistas: “(...) inserindo-se dentro de um processo de conhecimento e interpretação da realidade nacional [o movimento] não ficou apenas no desmascaramento da estética passadista, mas procurou abalar toda uma visão do país que subjazia à produção anterior à sua atividade.”16

\section{MODERNISMO E CRÍTICA LITERÁRIA}

No livro 1930: a crítica e o modernismo, João Luiz Lafetá faz uma análise da crítica literária brasileira na década de 1930, a fim de avaliar o impacto do modernismo na crítica. Para tanto, ele escolhe críticos que incorporaram mais ou menos em seu exercício as exigências impostas pela nova literatura surgida a partir da ruptura proporcionada pelo modernismo. O principal critério de avaliação dessa nova crítica literária, segundo o autor, é a incorporação de uma consciência aprofundada da linguagem, que vai muito além da tarefa rotineira da crítica. Uma vez que o movimento modernista teve como consequência do desnudamento dos procedimentos da linguagem na obra a consciência da própria linguagem, a tarefa da crítica se tornou mais complexa. Se antes seu papel era essa consciência, agora já praticada pela obra, dali em diante a crítica precisaria aumentar ainda mais o processo de conscientização, verificando se a literatura foi capaz de atingir seu novo propósito e até que ponto esse alcance se deu.

Como dito anteriormente, Lafetá considera que o modernismo tem intrínsecas duas esferas em constante tensão - a ideológica e a estética -, ora tendendo ao equilíbrio, ora ao atrito. O autor ressalta a importância da consciência dessa tensão permanente para a crítica. Entre os críticos por ele estudados, Mário de Andrade é o que apresenta a obra mais rica, e o principal motivo é que o crítico está sempre em busca de um aspecto fundamental do modernismo, ou seja, do equilíbrio entre o aspecto estético e o ideológico da literatura.

Em seu estudo sobre a crítica mariodeandradeana, Lafetá segue a trajetória do artista, do teórico e do crítico Mário de Andrade, acompanhando o desenvolvimento de seu pensamento e de sua prática artística, desde sua “fase heroica”, em que o escritor-teórico precisa defender uma nova forma de arte por meio de novos parâmetros estéticos, no

\footnotetext{
${ }^{16}$ LAFETÁ. 1930: a crítica e o modernismo, p. 21.
} 
“Prefácio interessantíssimo”, até a década de 1930, em que o escritor publica “O carro da miséria” e o crítico escreve os ensaios que serão posteriormente editados nos livros $O$ empalhador de passarinho e Aspectos da literatura brasileira. Mário de Andrade demonstra desde o início um esforço crítico e teórico grande, mostrando um conhecimento profundo das tendências das vanguardas europeias. Se, na primeira fase, ele parece favorecer o enfoque individual da obra de arte, o lirismo, isso se dá graças à necessidade de que tratamos anteriormente de romper com uma concepção parnasiana de arte, em que o artista fica sujeito a regras rígidas de conduta, sob as quais muitas vezes sucumbe a liberdade produtiva. No entanto, ele jamais deixa de perceber a importância do caráter estético da obra de arte, a técnica, sempre buscando um ponto de equilíbrio entre esses dois enfoques e também, devido à sua condição de vanguardista, buscando novos parâmetros estéticos - como a teoria do "polifonismo" -, que fossem capazes de fundamentar sua arte.

Após encontrar um ponto de equilíbrio entre esses dois enfoques da arte - o que fica claro já em A escrava que não é Isaura, surge um novo impasse. O escritor precisa se ajustar novamente, agora a uma outra exigência: o caráter social, público, da obra de arte. A eficaz combinação entre a ruptura da linguagem e a crítica social terá sua síntese na obra publicada em 1930, “O carro da miséria”. Consciência que o crítico Mário de Andrade atingirá somente no final da década, com uma nova concepção de técnica e de arte. Para Lafetá, o crítico expõe pela primeira vez essa nova ideia na conferência “O artista e o artesão”, de 1938: “Aqui Mário de Andrade ampliou consideravelmente o seu conceito de 'técnica', tornando-se capaz de abranger tanto o lirismo individual como as condições sociais em que o artista produz sua obra”. 17

Se fizermos uma comparação entre o estudo de Lafetá e a conferência de Mário de Andrade, torna-se visível que a avaliação deste crítico está de acordo com a do estudo posterior. Por ter uma visão temporalmente mais distanciada, Lafetá percebe o movimento em várias fases, percepção que diverge das de Mário de Andrade e Álvaro Lins, que na década de 1940 já consideram o modernismo como terminado e avaliam a literatura da época como uma consequência do movimento. Não é interesse para o presente trabalho entrar a fundo nessas classificações. Mas é válido ressaltar que as avaliações convergem ao constatar um predomínio do âmbito estético nas obras literárias produzidas na década de 1920; na segunda fase, que Mário de Andrade já não considera como parte do movimento, mas como consequência dele, é que foi possível um avanço maior no âmbito político-social, uma vez

\footnotetext{
${ }^{17}$ LAFETÁ. 1930: a crítica e o modernismo, p. 211.
} 
que a vanguarda já havia conquistado a liberdade de criação estética. Graças à estabilização dessa conquista, os artistas foram capazes de se debruçar sobre esse outro aspecto da arte.

É importante ressaltar que o crítico Mário de Andrade teve consciência dessa transformação, o que se demonstra com a leitura de seus ensaios críticos sobre as produções literárias da época. Seu embate com o constante conflito estético-ideológico é tão intenso e sem trégua que às vezes seu trabalho crítico parece se contradizer, pois ora defende a literatura como estética pura, ora como engajamento social. No entanto, para Lafetá, essa aparente contradição é um exercício de consciência, uma tentativa de não se deixar levar pelas influências do momento. Seu esforço é de não perder de vista a tensão entre os dois polos da arte, tentando chamar a atenção para um aspecto, na medida em que percebe que numa dada obra ou num dado contexto está excessivamente prejudicado em relação ao outro.

\section{CONCLUSÃO}

Conforme explicitado anteriormente, as contribuições do modernismo não foram homogêneas e atingiram níveis diferentes de ruptura. Enquanto alguns artistas e alguns setores da sociedade conseguiram ir mais fundo e atingir transformações de maior vulto, outros permaneceram na superfície dessas transformações. Esse fenômeno é comum em movimentos artísticos. Da mesma forma, é natural que um movimento se dilua após um tempo de assimilação e dê a sensação de que as conquistas da fase mais radical tenham se perdido, ou mesmo retrocedido a uma fase anterior de estagnação. Isso de fato pode ocorrer, mas somente de forma parcial. No momento de diluição de um movimento, a arte, a literatura, e a sociedade já adquiriram valores conquistados com a ruptura inicial, pelo menos aqueles valores que ela estava pronta para incorporar.

Tendo esse ponto de vista como parâmetro para o presente trabalho, foi escolhido um representante da "ala” mais radical do modernismo. Sua radicalidade está no fato de ter conseguido atingir as mudanças mais representativas, tanto no âmbito estético, pois conseguiu de fato por em prática uma linguagem inovadora, quanto no âmbito político-social, pois não abriu mão da visão crítica, apartidária e autônoma sobre as questões do seu tempo.

Para concluir, procuraremos entender o que fez com que essa vertente do modernismo se tornasse a mais efetiva e, consequentemente, a mais representativa do movimento. Para tanto, procuraremos avaliar melhor o que significa a atitude consciente do escritor e do crítico Mário de Andrade. O fato de ter conseguido atingir os maiores avanços estéticos e críticos pode se explicar em parte pela forma como ele viu a ruptura: seu senso apurado do espírito do 
seu tempo e do seu lugar na história o ajudou a ter uma atitude vanguardista, não de rebeldia contra o que oprimia sua arte e seu pensamento, mas de real autonomia, aceitando e incorporando o que a tradição e o centro tinham de produtivo e negando e transfigurando aquilo que não interessava. A consequência desse posicionamento autônomo foi que o autor não se deixou levar pelo ufanismo, nem pela repulsa cega dos padrões questionados, o que mostra uma atitude madura, apesar de revolucionária.

Enquanto alguns vanguardistas insistiam numa atitude de pura revolta contra Portugal, por exemplo, Mário de Andrade em momento algum - a não ser logo no início, talvez pensou em construir uma literatura brasileira sem qualquer tipo de influência ou diálogo com o passado ou com a literatura universal. Eneida Maria de Souza lembra a atitude do autor diante da cultura da metrópole, aquela que será muito bem elaborada pela antropofagia:

(...) o "esquecimento" da cultura imposta pela metrópole seria o antídoto eficaz a ser utilizado na luta a favor da independência cultural, pela desobediência do colonizado frente à marca registrada das idéias e modelos do colonizador. Esse esquecimento não implicaria, evidentemente, a destruição de uma memória acumulada, mas a prática de transgressão e releitura dos modelos. ${ }^{18}$

Dessa forma, por mais que o modernismo tenha chegado a um estágio de diluição dos padrões estéticos, como conclui melancolicamente Álvaro Lins na década de 1960, chegando ao "abandono do brasileirismo que vinha caracterizando a nossa literatura desde o advento do movimento modernista”, ${ }^{19}$ não se pode negar que muitos valores cultivados pelo movimento foram incorporados à literatura e à crítica brasileiras, ou pelo menos em uma parcela dessa produção. Vários de nossos autores foram capazes de criar uma literatura brasileira, no que tem de peculiar, de original, e ao mesmo tempo universal, pois não ficou impregnada de clichês e maneirismos regionalistas. Podem ser citadas, como exemplo do que acabamos de afirmar, obras literárias como as de Carlos Drummond de Andrade, João Cabral de Melo Neto e Graciliano Ramos. Entre as produções críticas, também houve êxito na busca por uma consciência aprofundada da linguagem. Estudos como os de Antonio Candido e Álvaro Lins, por exemplo, conseguiram incorporar as exigências modernas da crítica literária e deixaram contribuições de vulto para a sistematização da literatura brasileira.

\footnotetext{
${ }^{18}$ SOUZA. A pedra mágica do discurso. Jogo e linguagem em Macunaíma, p. 26. (grifos nossos)

${ }^{19}$ LINS. A liderança literária, o ensaio e a crítica em Mário de Andrade, p. 123.
} 


\section{ABSTRACT}

The objective of this paper is to investigate in which way the Brazilian modernist movement has contributed to the formation or the consolidation of a Brazilian modern literature, through the renovation of aesthetic and social-political patterns, on one hand, and on the other, what heritage has the movement left to the national critical production.

KEYWORDS

Modernism, Brazilian literature, Brazilian literary critics

\section{REFERÊNCIAS}

ANDRADE, Mário de. O movimento modernista. In: Aspectos da literatura brasileira. São Paulo: Martins, 1974. p. 231-254.

BOAVENTURA, Maria Eugênia. Movimento brasileiro: contribuição ao estudo do modernismo. São Paulo: Secretaria da Cultura, Ciência e Tecnologia, Conselho Estadual de Artes e Ciências Humanas, 1978.

BOAVENTURA, Maria Eugênia (Org.). 22 por 22. A Semana de Arte Moderna pelos seus contemporâneos. São Paulo: Edusp, 2000.

LAFETÁ, João Luiz. 1930: a crítica e o modernismo. São Paulo: Duas Cidades/Editora 34, 2000.

LINS, Álvaro. A liderança literária, o ensaio e a crítica em Mário de Andrade. In:

Filosofia, história e crítica na literatura brasileira: Afrânio Peixoto, João Ribeiro, José Veríssimo, Mário de Andrade, Lúcia Miguel Pereira. Rio de Janeiro: Tecnoprint, 1967. p. 7279.

LINS, Álvaro. Por uma história literária do Brasil e por uma literatura brasileira. In:

Filosofia, história e crítica na literatura brasileira: Afrânio Peixoto, João Ribeiro, José Veríssimo, Mário de Andrade, Lúcia Miguel Pereira. Rio de Janeiro: Tecnoprint, 1967. p. 113-123.

SCHWARTZ, Jorge. Vanguardas latino-americanas: polêmicas, manifestos e textos críticos. São Paulo: Edusp, 1995.

SOUZA, Eneida Maria de. A pedra mágica do discurso. Jogo e linguagem em Macunaíma. Belo Horizonte: Editora UFMG, 1988. 